\title{
Meningococcal group C conjugate vaccines
}

In November 1999 the Department of Health introduced a national vaccination programme using newly licensed meningococcal serogroup $\mathrm{C}$ conjugate vaccines (MenC). ${ }^{1}$ In the largest national mass vaccination campaign ever undertaken in the UK, all people under the age of 18 years are being offered vaccination: three doses for infants as part of the primary vaccination schedule at 2,3 , and 4 months of age; two doses for infants age 4-12 months; and one dose for individuals aged 1-18 years. The cost to the government has not been made public. Vaccination started a year earlier than originally planned and the UK is the only country thus far to have licensed and introduced the vaccine. Prior to the campaign there was no experience of using the vaccine outside the setting of a clinical trial. What is the rationale behind this ambitious programme and what unanswered questions remain?

\section{The burden of disease}

Every paediatrician knows the severity of invasive meningococcal disease and the speed at which previously healthy children can become prostrate. Five major serogroups (A, $\mathrm{B}, \mathrm{C}, \mathrm{Y}$, and $\mathrm{W} 135$ ) are responsible for the majority of disease, the serogroup being determined by the nature of the capsular polysaccharide. The prevalence of different serogroups varies in different regions and in different age groups. Globally the greatest burden of disease comes from serogroup A which is responsible for massive epidemics in the "meningitis belt" of sub-Saharan Africa and an endemic rate which is more than 10 times that in industrialised countries. ${ }^{2}$ In much of Western Europe including the UK, more than $90 \%$ of disease is caused by serogroups B and C. Serogroup C accounts for $25-40 \%$ of cases, with the relative proportion varying in a cyclical manner from year to year. In 1995, there were 1890 reported cases of invasive meningococcal disease, an increase of $43 \%$ on the previous year. ${ }^{3}$ The majority of the increase was caused by serogroup C. Numbers of reported cases continued to rise in subsequent years, reaching a 50 year high in 1997 of 2659. ${ }^{4}$ The rise in numbers may be partly a result of better case ascertainment, but it has also coincided with the emergence of a new serogroup C clone named "ET-37" which has been responsible for a number of outbreaks of disease in many countries around the world..$^{5-12}$ Many of these have attracted intense media attention. By far the majority of people with invasive disease are healthy individuals under the age of 20 with no apparent risk factors for disease. The peak incidence of disease is in infants under 1 year of age with a second peak in older teenagers. ${ }^{13}$ While $40 \%$ of disease is caused by group C in all age groups, there are more deaths attributed to serogroup $\mathrm{C}$ than serogroup B in the 11-24 year age group. ${ }^{14}$

\section{Development of natural immunity}

Development of effective vaccines requires an understanding of the development of natural immunity. The incidence of disease in the first six months of life is low, suggesting that maternal antibody acquired transplacentally or through breast milk protects against disease. Nasopharyngeal carriage of Neisseria meningitidis is low during early childhood, but carriage of commensal Neisseria species such as $N$ lactamica is common..$^{15}$ Exposure to these and other cross reacting antigens, for example the polysaccharides of Escherichia coli $\mathrm{K} 51$ and K53, are thought to result in an antibody response to common antigens which protect against disease. ${ }^{16-18}$ Concentrations of bactericidal anti- bodies increase during childhood and adolescence, and in the case of serogroups $\mathrm{A}$ and $\mathrm{C}$, this correlates with protection against disease. ${ }^{16}$ About $25 \%$ of young adults harmlessly carry $N$ meningitidis in the oropharynx. It is thought that this exposure continually stimulates an immune response, providing ongoing protection against invasive disease.

MenC vaccination aims to provide protection by stimulating the development of bactericidal antibodies directed at the polysaccharide capsule. While these are an important component of immunity, ${ }^{16}$ antibodies to other cell wall constituents such as outer membrane proteins and lipopolysaccharide are also thought to make a contribution. In addition to specific antibody and cell mediated mechanisms of immunity, non-specific mechanisms including complement activation, non-specific opsonisation, and phagocytosis are likely to be important in protecting against disease. The integrity of the oropharyngeal mucosa and mucosal immunity in the form of salivary antibodies may also play a role in preventing invasion.

How does the new MenC conjugate vaccine differ from meningococcal polysaccharide vaccines? Purified polysaccharide vaccines containing either $\mathrm{A} / \mathrm{C}$ or A/C/W135/Y polysaccharides have been licensed for 25 years. Efficacy studies of group A polysaccharide have shown good short term efficacy of $85 \%$ or more in older children and adults. They are currently recommended for use in military recruits, control of outbreaks, and for travel to areas of high endemicity such as the Hajj. ${ }^{14}$ Similar levels of efficacy have been reported for serogroup C polysaccharide in adults. ${ }^{19-21}$ Children less than 5 years of age, however, have a limited response to purified group C polysaccharide, ${ }^{22}{ }^{23}$ immunity is short lived, ${ }^{24}$ and there are concerns that repeated doses of group C polysaccharide induce a degree of hyporesponsiveness, ${ }^{25-27}$ a phenomenon which might also extend to adults. ${ }^{28-30}$ For these reasons polysaccharide vaccines have never been recommended for routine use in childhood immunisation programmes.

MenC conjugate vaccines use the same technology as the highly successful protein-polysaccharide Haemophilus influenzae type $\mathrm{B}$ (Hib) conjugate vaccines. ${ }^{31}$ Conjugation of the serogroup $\mathrm{C}$ oligosaccharide to a protein carrier, such as tetanus toxoid, facilitates $\mathrm{T}$ cell help and switches the immune response from a thymus independent to a thymus dependent one. ${ }^{32}$ This results in an effective primary antibody response in all age groups, including infants. Additionally it allows rapid, anamnestic antibody responses on future exposure to the antigen (called immunological memory).

A number of factors combined during the mid 1990s to create the environment for a major momentum to speed up licensing of the MenC vaccines: there was increasing morbidity and mortality caused by group $\mathrm{C}$ disease; public awareness was heightened through intense media attention and demand for a vaccine increased; Hib conjugate vaccine had a dramatic impact on Hib disease ${ }^{31}$; and results of early clinical trials using MenC conjugate vaccines during the mid 1990s were promising. ${ }^{26}{ }^{33-36}$ The Public Health Laboratory Service conducted its own programme of independent clinical trials to determine the safety and immunogenicity of candidate MenC vaccines in different age groups. ${ }^{3037}{ }^{38}$ While most of these trials did not include a randomised control group, they nevertheless provided valuable information and helped to fulfil the requirements for licensing. 
Assessment of the response to MenC vaccination Two methods are commonly used to assess the humoral immune response to vaccination: enzyme linked immunosorbent assay (ELISA) and serum bactericidal assay (SBA). A standardised MenC ELISA measures serum IgG antibody against MenC polysaccharide ${ }^{39}$ and assays antibodies of both low and high affinity. SBA measures the functional activity of serum by determining the dilution of heat inactivated sera required to produce at least 50\% killing of bacteria by complement mediated lysis. ${ }^{40}$ While most studies have used these standardised assays, they do not always correlate well, ${ }^{23}$ and others have altered the assay conditions. For example, a modified ELISA has been developed which selectively measures high affinity antibodies and results in a better correlation with SBA titres. ${ }^{41}$ Others have varied the source of complement. ${ }^{42}$ This may be important as the correlation between an SBA titre of greater than $1 / 4$ and natural protection against disease was performed using human complement, ${ }^{16}$ and the standardised SBA assay uses baby rabbit complement. ${ }^{40}$ The titre which correlates with protection following vaccination is not known.

\section{Clinical trials using meningococcal conjugate vaccines}

Published clinical trials have used both group C or combined groups $\mathrm{A}$ and $\mathrm{C}$ conjugate vaccines. Conjugate vaccines containing A, C, W135, and Y are in early development. The group B polysaccharide is poorly immunogenic in man and although one MenB Ps-protein conjugate vaccine remains under development, other approaches are being used to develop vaccines against this serogroup. Three MenC vaccines have been licensed in the UK. Two contain $10 \mu \mathrm{g}$ of group $\mathrm{C}$ oligosaccharide conjugated to $\mathrm{CRM}_{197}$, a non-toxic mutant of diphtheria toxin, the other uses tetanus toxoid as the carrier protein. ${ }^{38}$ Studies of these vaccines have been carried out in all the relevant age groups, namely infants, toddlers, preschool children, teenagers, and young adults. ${ }^{26} 33-353743-46$

The first priority of any vaccine is safety, and all studies have shown a very acceptable safety profile. ${ }^{26}$ 33-35 37 43-47 The most common local reactions in infants and toddlers include redness, tenderness, and swelling at the injection site, irritability, and fever. ${ }^{48}$ Headaches and malaise occur in about $10 \%$ of older children and teenagers. ${ }^{46}$ While no serious adverse effects were noted in clinical trials, rare but serious adverse effects cannot be excluded and may become apparent when a large population is vaccinated. As the vaccine was licensed with relatively limited safety data, post marketing surveillance is vital. Paediatricians should report any serious or uncommon side effect which may be attributed to MenC vaccination through the yellow card system.

Good primary antibody responses have been shown in all age groups following MenC vaccination. In addition, immunological memory has been shown by determining antibody responses after a booster of meningococcal polysaccharide. ${ }^{263743-45}$ Studies have given the vaccine either alone or in combination with other routine infant vaccinations. These studies show no adverse effect on the response to routine infant vaccinations.

\section{Does MenC vaccination prevent disease?}

This is probably the most important unanswered question. As group $\mathrm{C}$ meningococcal disease is rare, randomised controlled efficacy studies would involve hundreds of thousands of participants and would take years to complete. Based on a good primary immune response, high levels of bactericidal activity, the demonstration that these vaccines induce immunological memory, and experience with Hib conjugate vaccines, the vaccine has been licensed and introduced without efficacy studies. The current UK MenC vaccination campaign could be considered as an uncontrolled effectiveness study. The real impact of vaccination may be hard to assess given the cyclical nature of the proportion of disease caused by any given serogroup. However, it is probable that MenC vaccines will be highly effective against group $\mathrm{C}$ disease and that the number of cases of invasive group C disease will dramatically fall. Indeed, early results suggest this to be the case as the number of notifications of group $\mathrm{C}$ disease in vaccinated groups over the winter of $1999 / 2000$ were significantly fewer than would be predicted. ${ }^{49}$

\section{Possible limitations of MenC vaccination}

Unlike Hib disease which is caused by just one serotype, invasive meningococcal disease is caused by several different serotypes. There is therefore a theoretical concern that immune pressure from widespread serogroup $C$ vaccination might be sufficient to promote the spread of "escape mutants" through strain replacement or capsular switching. ${ }^{50}$ Almost all serogroup $\mathrm{C}$ meningococcal disease in the UK is caused by strains of the "ET-37 complex" lineage which, while predominantly serogroup $C$, can possess other capsules and remain virulent. ${ }^{51}$ The impact of MenC vaccination on the rate of overall disease would be attenuated if there were emergence of disease caused by other capsular serogroups. ${ }^{52}$ This danger has been highlighted recently by an outbreak among Haji pilgrims, caused by serogroup W-135 meningococci, which are ET-37 variants. ${ }^{53}$ Information is required on the effect of vaccination on the rates of carriage and circulating strains of meningococci, as a reduction in carriage may confer a degree of herd immunity. There is published evidence that MenC vaccines induce mucosal antibody, which suggests that they may reduce carriage of serogroup C meningococci, ${ }^{54} 55$ although this remains to be seen. Dependent on continued funding, it is anticipated that a large scale carriage study in teenagers, who were swabbed before receiving MenC in 1999 , will provide some of this vital information.

\section{Future questions to be addressed}

An additional, but vital question, is the duration of protection that $\mathrm{MenC}$ vaccination will provide. Unlike Hib disease which is rare beyond 5 years of age, the risk of meningococcal disease extends into early adulthood. Protection probably relates both to sustained levels of antibactericidal antibody as well as the presence of immunological memory. It may be that immunological memory is sufficient in the presence of even low antibody levels. This is important as antibody levels can fall rapidly following MenC vaccination. In one study, after receiving MenC at 2 , 3, and 4 months of age, only $75 \%$ of 12 month old children had levels of bactericidal antibody titre greater than $1 / 4$, the proposed level of protection. ${ }^{43}$ Therefore the presence of immunological memory is likely to be critical in providing continued protection. It is not known whether a single dose of MenC results in life long memory. The only study following antibody levels more than two years after vaccination showed immunological memory to group $\mathrm{C}$ polysaccharide in 5 year old Gambian children who had been vaccinated with meningococcal $\mathrm{A} / \mathrm{C}$ conjugate vaccine in infancy, although resting antibody levels were low. ${ }^{56}$ If a MenC booster is required, the timing still needs to be determined, but logically would be either at 13-15 months of age with MMR, or at 4-5 years with the routine preschool boosters.

The choice of carrier protein may become an important issue as other conjugate vaccines are added to the routine infant vaccination programme. The common carrier 
proteins are already administered as part of the routine schedule in the form of diphtheria and tetanus toxoids. This has the advantage that their safety profiles are known, but higher doses of protein, as part of the conjugate vaccines, may result in increased rates of local reactions, and possible immunological interference. "Carrier induced epitope suppression" is one proposed mechanism for this where exposure to the carrier protein results in expansion of carrier specific B cells, directing the immune response away from capsular specific B cells, and leading to a reduced antibody response. ${ }^{57}$

With ever increasing numbers of childhood vaccinations, many parents are concerned about the number of needles their children receive. The combination of MenC with other childhood vaccines such as pneumococcal and Hib conjugates is an attractive approach which is currently being pursued.

Close contact of cases of group C meningococcal infection should be given meningococcal vaccine in addition to chemoprophylaxis. The Department of Health advises that meningococcal A/C polysaccharide should be used except in contacts less than 2 years of age until sufficient stocks of MenC conjugate vaccine accumulate. ${ }^{14}$ This policy will be reviewed and it is likely that MenC conjugate will be recommended for all close contacts of index cases in the near future. Meningococcal A/C polysaccharide vaccine is still recommended for travel to areas of high endemicity, even in individuals who have received MenC conjugate. ${ }^{14}$ Although studies have shown that MenC conjugate can overcome hyporesponsiveness induced by meningococcal group C polysaccharide, ${ }^{27}{ }^{40} 47$ the effect of mixing polysaccharide and conjugate vaccine schedules in this way requires further investigation. The best approach in the long run may be the development of global conjugate vaccines containing A, C, W135, and Y oligosaccharides, or ideally the development of vaccines based on other antigens which are shared by all meningococci (including serogroup B). These approaches will be suitable for routine use in industrialised and non-industrialised nations and obviate the need for specific meningococcal "travel" vaccination.

\section{Conclusion}

Paediatricians should welcome the introduction of routine MenC vaccination in the UK. These vaccines have a good safety profile and they induce immunological memory in addition to high levels of bactericidal antibody in all age groups. It is expected that the national campaign will be highly effective at reducing the $40 \%$ of meningococcal disease that is caused by group C, although efficacy studies have not been performed. Strain replacement and capsular switching may limit the long term effectiveness of group C conjugate vaccines, and this concern highlights the need for careful ongoing disease surveillance. In the absence of effective vaccines against all serogroups of $N$ meningitidis, the MenC vaccine will, at best, prevent less than half of all cases of disease. Parents and physicians should therefore continue to be vigilant in examining for signs of meningococcal disease in sick children.

Many thanks to Paul Heath, Jane Crawley, Karen Sleeman, and Robert Booy for helpful discussions and critical reading of the manuscript.

J MACLENNAN

Wellcome Trust Centre for the Epidemiology of Infectious Diseases, Department of Zoology, University of Oxford, South Parks Road, Oxford OX1 3FY, UK

Correspondence to: Dr MacLennan

jenny.maclennan@ceid.ox.ac.uk

1 Anonymous. Vaccination programme for group C meningococcal infection is launched. Commun Dis Rep CDR Wkly 1999;9:261,264.
2 Robbins JB, Towne DW, Gotschlich EC, Schneerson R. "Love's labours lost": failure to implement mass vaccination against group A meningococcal meningitis in sub-Saharan Africa. Lancet 1997;350:880-2.

3 Kaczmarski EB. Meningococcal disease in England and Wales: 1995. Commun Dis Rep CDR Rev 1997; 7:R55-9.

4 Anonymous. Infectious disease in England and Wales: October to December 1998. Commun Dis Rep CDR Suppl 1999;9:S5.

5 Wang JF, Caugant DA, Morelli G, et al. Antigenic and epidemiologic properties of the ET-37 complex of Neisseria meningitidis. F Infect Dis 1993;167:1320-9.

6 Raymond NJ, Reeves M, Ajello G, et al. Molecular epidemiology of sporadic (endemic) serogroup C meningococcal disease. F Infect Dis 1997;176: $1277-84$.

7 Sacchi CT, Zanella RC, Caugant DA, et al. Emergence of a new clone of serogroup C Neisseria meningitidis in Sao Paulo, Brazil. f Clin Microbiol 1992;30:1282-6.

8 Jackson LA, Schuchat A, Reeves MW, Wenger JD. Serogroup C meningococcal outbreaks in the United States. An emerging threat. $\mathscr{f} A M A$ 1995;273:383-9.

9 Whalen CM, Hockin JC, Ryan A, Ashton F. The changing epidemiology of invasive meningococcal disease in Canada, 1985 through 1992. Emergence of a virulent clone of Neisseria meningitidis. $¥ A M A$ 1995;273:390-4.

10 Fogarty, J. Trends in serogroup C meningococcal disease in the Republic of Ireland. Eurosurveillance 1998;2:75-6.

11 Mateo S, Cano R, Garcia C. Changing epidemiology of meningococcal disease in Spain, 1989-1997. Eurosurveillance 1998;2:71-4

12 Gilmore A, Jones G, Barker M, et al. Meningococcal disease at the University of Southampton: outbreak investigation. Epidemiol Infect 1999;123: 185-92.

13 Noah N, Connolly M. Surveillance of bacterial meningitis in Europe 1995. King's College, London, 1996.

14 Salisbury DM, Begg NT, eds. Meningococcal infection. In: Immunisation against infectious disease. London: Department of Health, 1996.

15 Gold R, Goldschneider I, Lepow ML, et al. Carriage of Neisseria meningitidis and Neisseria lactamica in infants and children. F Infect Dis 1978;137: $112-21$.

16 Goldschneider I, Gotschlich EC, Artenstein MS. Human immunity to the meningococcus. II. Development of natural immunity. $f$ Exp Med 1969;129:1327-48.

17 Robbins JB, Myerowitz L, Whisnant JK, et al. Enteric bacteria cross-reactive with Neisseria meningitidis groups $\mathrm{A}$ and $\mathrm{C}$ and Diplococcus pneumoniae types I and 3. Infect Immun 1972;6:651-6.

18 Guirguis N, Schneerson R, Bax A, et al. Escherichia coli K51 and K93 capsular polysaccharides are crossreactive with the group A capsular polysaccharide of Neisseria meningitidis. Immunochemical, biological, and epidemiological studies. 7 Exp Med 1985;162:1837-51.

19 Artenstein MS, Gold R, Zimmerly JG, et al. Prevention of meningococcal disease by group C polysaccharide vaccine. N Engl f Med 1970;282:41720.

20 Gold R, Artenstein MS. Meningococcal infections. 2. Field trial of group C meningococcal polysaccharide vaccine in 1969-70. Bull World Health Organ 1971;45:279-82.

21 De Wals P, Dionne M, Douville Fradet $M$, et al. Impact of a mass immunization campaign against serogroup $\mathrm{C}$ meningococcus in the Province of Quebec, Canada. Bull World Health Organ 1996;74:407-11.

22 King WJ, MacDonald NE, Wells G, et al. Total and functional antibody response to a quadrivalent meningococcal polysaccharide vaccine among children. F Pediatr 1996;128:196-202.

23 Maslanka SE, Tappero JW, Plikaytis BD, et al. Age-dependent Neisseria meningitidis serogroup C class-specific antibody concentrations and bactericidal titers in sera from young children from Montana immunized with a licensed polysaccharide vaccine. Infect Immun 1998;66:2453-9.

24 Reingold AL, Broome CV, Hightower AW, et al. Age-specific differences in duration of clinical protection after vaccination with meningococcal polysaccharide vaccine. Lancet 1985;2:114-18.

25 Gold R, Lepow ML, Goldschneider I, Gotschlich EC. Immune response of human infants to polysaccharide vaccines of group A and C Neisseria meningitidis. F Infect Dis 1977;136(suppl):S31-5.

26 Leach A, Twumasi PA, Kumah S, et al. Induction of immunologic memory in Gambian children by vaccination in infancy with a group A plus group $\mathrm{C}$ meningococcal polysaccharide-protein conjugate vaccine. f Infect Dis 1997; 175:200-4.

27 MacLennan J, Obaro S, Deeks J, et al. Immune response to revaccination with meningococcal A and C polysaccharides in Gambian children followwith meneated immunisation during early childhood. Vaccine 1999;17:3086ing rep

28 Artenstein MS, Brandt BL. Immunologic hyporesponsiveness in man to group C meningococcal polysaccharide. F Immunol 1975;115:5-7.

29 Granoff DM, Gupta RK, Belshe RB, Anderson EL. Induction of immunologic refractoriness in adults by meningococcal $\mathrm{C}$ polysaccharide vaccination. F Infect Dis 1998;178:870-4.

30 Richmond P, Kaczmarski E, Borrow R, et al. Meningococcal C polysaccharide vaccine induces immunologic hyporesponsiveness in adults that is overcome by meningococcal C conjugate vaccine. F Infect Dis 2000;181: $761-4$.

31 Heath PT. Haemophilus influenzae type b conjugate vaccines: a review of efficacy data. Pediatr Infect Dis $\mathcal{F} 1998 ; 17:$ S117-22.

32 Siber GR. Pneumococcal disease: prospects for a new generation of vaccines. Science 1994;265:1385-7.

33 Twumasi PA Jr, Kumah S, Leach A, et al. A trial of a group A plus group C meningococcal polysaccharide-protein conjugate vaccine in African infants. F Infect Dis 1995;171:632-8.

34 Fairley CK, Begg N, Borrow R, et al. Conjugate meningococcal serogroup A and $\mathrm{C}$ vaccine: reactogenicity and immunogenicity in United Kingdom infants. F Infect Dis 1996;174:1360-3.

35 Anderson EL, Bowers T, Mink CM, et al. Safety and immunogenicity of meningococcal $\mathrm{A}$ and $\mathrm{C}$ polysaccharide conjugate vaccine in adults. Infect Immun 1994;62:3391-5.

36 Lieberman JM, Chiu SS, Wong VK, et al. Safety and immunogenicity of a serogroups $\mathrm{A} / \mathrm{C}$ Neisseria meningitidis oligosaccharide-protein conjugate vaccine in young children. A randomized controlled trial. $\mathcal{F A M A} 1996 ; 275$ : 1499-503. 
37 Richmond P, Borrow R, Miller E, et al. Meningococcal serogroup C conjugate vaccine is immunogenic in infancy and primes for memory. F Infect $D$ is gate vaccine is immun

38 Richmond P, Goldblatt D, Fusco PC, et al. Safety and immunogenicity of a new Neisseria meningitidis serogroup C-tetanus toxoid conjugate vaccine in healthy adults. Vaccine 1999;18:641-6.

39 Gheesling LL, Carlone GM, Pais LB, et al. Multicenter comparison of Neisseria meningitidis serogroup $\mathrm{C}$ anti-capsular polysaccharide antibody levels measured by a standardized enzyme-linked immunosorbent assay. $\mathcal{F}$ Clin Microbiol 1994;32:1475-82.

40 Maslanka SE, Gheesling LL, LiButti DE, et al. Standardization and a multilaboratory comparison of Neisseria meningitidis serogroup A and C serum bactericidal assays. The Multilaboratory Study Group. Clin Diagn Lab Immunol 1997;4:156-67.

41 Granoff DM, Maslanka SE, Carlone GM, et al. A modified enzyme-linked immunosorbent assay for measurement of antibody responses to meningococcal C polysaccharide that correlate with bactericidal responses. Clin Diagn Lab Immunol 1998;5:479-85.

42 Borrow R, Richmond P, Kaczmarski EB, et al. Meningococcal serogroup C-specific IgG antibody responses and serum bactericidal titres in children following vaccination with meningococcal $\mathrm{A} / \mathrm{C}$ polysaccharide. FEMS

43 Maclennan JM, Shackley F, Heath PT, et al. Safety, immunogenicity, and induction of immunologic memory by a serogroup $\mathrm{C}$ meningococcal conjugate vaccine in infants: a randomized controlled trial. $\mathscr{f A M} A 2000 ; 281$ : 2795-801

44 Lieberman JM, Wong VK, Partridge S, et al. Bivalent A/C meningococcal conjugate vaccine in toddlers: persistence of antibodies and response to a polysaccharide vaccine booster (Poster 75) [abstract]. Abstracts of the 10th Neisseria Meeting, Baltimore. 1996:231-2.

45 MacDonald NE, Halperin SA, Law BJ, et al. Induction of immunologic memory by conjugated vs plain meningococcal $\mathrm{C}$ polysaccharide vaccine in toddlers: a randomized controlled trial. $\mathscr{f} A M A$ 1998;280:1685-9.
46 Choo S, Zuckerman J, Goilav C, et al. Immunogenicity and reactogenicity of a group $\mathrm{C}$ meningococcal conjugate vaccine compared with a serogroup $\mathrm{A}$ $\& \mathrm{C}$ meningococcal polysaccharide vaccine in adolescents in a randomised observer-blind controlled trial. Vaccine 2000,18.2686-92.

47 MacDonald NE, Halperin SA, Law BJ, et al. Can meningococcal C conjugate vaccine overcome immune hyporesponsiveness induced by previous administration of plain polysaccharide vaccine? [letter]. $\mathcal{F A M A} 2000 ; 283$ : 1826-7.

48 Donaldson L, Moores Y, Howe J. Start of the new meningococcal C conjugate vaccine immunisation programme. London: Department of Health, 1999.

49 Anonymous. Meningococcal disease falls in vaccine recipients. Commun Dis Rep CDR. Wkly 2000;10:133-6.

50 Swartley JS, Marfin AA, Edupuganti S, et al. Capsule switching of Neisseria meningitidis. Proc Natl Acad Sci U S A 1997;94:271-6.

51 Kwara A, Adegbola RA, Corrah PT, et al. Meningitis caused by a serogroup W135 clone of the ET-37 complex of Neisseria meningitidis in West Africa. Trop Med Int Health 1998;3:742-6.

52 Maiden MC, Spratt BG. Meningococcal conjugate vaccines: new opportunities and new challenges. Lancet 1999;354:615-16.

53 Anonymous. Meningococcal infection in pilgrims returning from the Haji. Commun Dis Rep CDR Wkly 2000;10:125.

54 Borrow R, Fox AJ, Cartwright K, et al. Salivary antibodies following parenteral immunization of infants with a meningococcal serogroup $\mathrm{A}$ and C conjugated vaccine. Epidemiol Infect 1999;123:201-8.

55 Zhang Q, Choo S, Everard J, et al. Mucosal immune responses to meningococcal group $\mathrm{C}$ conjugate and group $\mathrm{A}$ and $\mathrm{C}$ polysaccharide vaccines in adolescents. Infect Immun 2000;68:2692-7.

56 Maclennan JM, Obaro S, Deeks JJ, et al. Immunologic memory 5 years after meningococcal A/C conjugate vaccine in infancy. F Infect Dis 2001;183.

57 Dagan R, Eskola J, Leclerc C, Leroy O. Reduced response to multiple vaccines sharing common protein epitopes that are administered simultaneously to infants. Infect Immun 1998;66:2093-8.

\section{STAMPS IN PAEDIATRICS}

\section{Infant growth monitoring}

Infant growth monitoring has been publicly promoted on postage stamps for many years although infrequently. Some of the earliest stamps are from the French Colonies, and are illustrated by the Dahomey airmail stamp from 1942 as part of the Colonial Child Welfare Fund omnibus issue. The same stamp design was shared by seven of the French colonies at that time including the Ivory Coast, Mauritania, and Senegal. Growth charts appeared on the 1986 India stamp commemorating the 40th anniversary of UNICEF and the 10 cent stamp from St Vincent in 1987 for the Child Health Campaign.

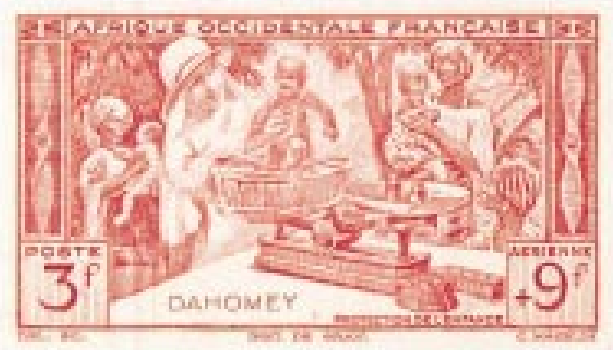

M K DAVIES

A J MAYNE
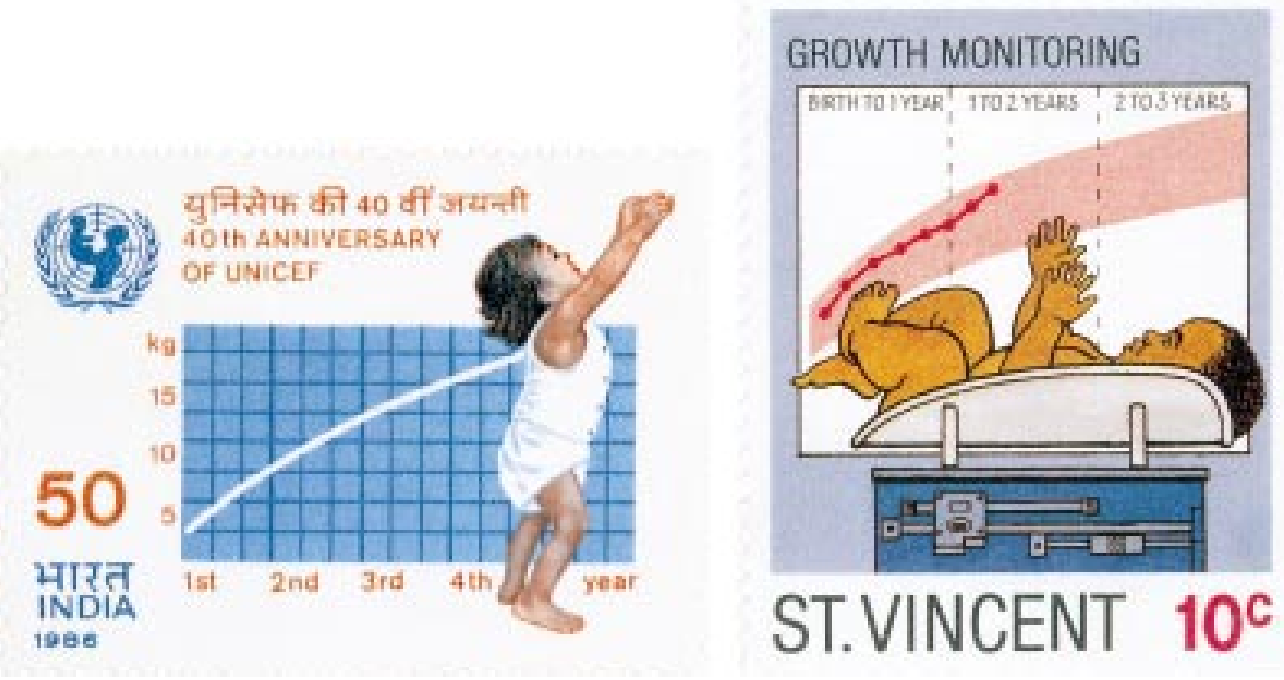